\title{
IMPROVING THE EDUCATION IN PATHOPHYSIOLOGY BY BRINGING IN CLINIACAL CASES DURING SEMINAR LESSONS
}

\author{
Radev R. Zl., G. Bekyarova, M. Marinov, K. Mirchev, M. Hristova \\ Faculty of Pathophysiology, Medical University - Varna
}

Reviewed by: Assoc. Prof. N. Negrev, MD, PhD

\begin{abstract}
Nowadays, high quality education is the centre of attention in every medical school. Searching for new ways to introduce the educational units is a natural drift for every discipline. Introducing new educational technique: "Solving of Clinical Case", aims at building a spontaneous bridge between preclinical knowledge and future work in the hospital in immediate and unattended contact with patients. Clinical case solving is a prerequisite for increasing the motivation of students, enhancing logical thinking and stimulating the student for additional investigation at home. The clinical case is based on real patients and the history of their diseases and it is related to the topic of the exercise. It includes the whole data from the moment the patient is seen by doctor for the first time until definitive diagnosis is formulated and medication prescribed.

The clinical case is divided in two parts, discussed in two subsequent seminar classes. During the first part the tutor does not give any additional information about the case, he just guides the discussion. The students work by themselves, formulate hypothesis and argument them by building logical connections between causes and results, using the model: causes (and conditions) - altered structure - harmed function - clinical symptom - set of symptoms (syndromes) - disease. At the end of the first part hypothesis are rearranged by their probability. The students may use the time between the to parts to find additional information on the topic and gain some knowledge on the hypothesis that have been discussed, using either traditional forms of education - textbooks, monographies, lectures, original scientific issues and reviews or any kind of source including the www. The second part is used for discussing what kind of laboratory, functional or instrumental tests are still needed to prove or exclude the hypothetical diagnosis.

The way it is created, every clinical case emphasizes not only on the biomedical side of the patient's problem, but also the socio-judicial aspects.
\end{abstract}

Keywords: new education technique, clinical case, pathophysiology

\section{INTRODUCTION}

The high quality of education is in the centre of attention of every medical school. An innovative approach towards medical education requires not only changes in traditional learning curricula (5) but also changes in the way material is introduced to the student (15). Searching for new ways to introduce the educational units to the students is a natural drift for every discipline (12). The end goal is helping the formation of professionals of high competency. This very kind of young doctors, having as a foundation a blend of knowledge, skills and practices acquired during the processes of education will be able to meet the requirements of EU member-countries for this kind of professionals (3).The analysis of "Status quo", following the in the course of education, shows that there is a big gap between research and practice. It takes too long until the scientific discovery goes all the way to practical application and teaching (6).

Medical students in our university seem to be poorly motivated to use original sources both new issues and reviews. It appears that most of them prefer to use just the textbooks or short versions, most of which are too old and cannot replace the real knowledge come from original materials (13). There are researches suggesting that introduction problem-based education in medical studies is successful and also increases the level of interest in the subject $(1,2,8$, 14). This kind of education shows good results world-wide. The students are working in small groups - discussing and interpreting the given data thus the processes of education is being brought maximally near to clinical subjects, connecting structure and function (7). Plays a key role in connecting basic preclinical disciplines: biochemistry, biophysics, physiology and anatomy on one hand, and on the other hand clinical disciplines: internal diseases, surgery, neurology, etc (4). In addition, vast knowledge in the field of physiology and pathophysiology is a prerequisite for adequate acquisition of general principals in pathology and pharmacology (11). The considerations stated above in combination with the experience of own colleagues in the Medical University - Pleven encouraged us to include new educational technique as a part of the education on pathophysiology since 2004 - "Solving of Clinical Case" .It 
aims at building a spontaneous bridge between preclinical knowledge and future work in the hospital in immediate and unattended contact with patients. Clinical case solving is a prerequisite to increasing the motivation of the students, enhancing logical thinking and stimulating the student for additional investigation at home.

\section{MATERIALS AND METHODS}

The clinical case is prepared by co-worker in the faculty of Pathophysiology in MU - Varna. It is based on real patients and the history of their diseases and it is related to the topic of the exercise. It includes the whole data from the moment the patient is seen by doctor for the first time till diagnosis is formulated and medication prescribed. The clinical case in divided in two parts which are discussed in two subsequent seminar classes (exercises in pathophysiology).

The part consists of:

\section{A. FIRST PART}

1. Brief presentation of a real patient but under false name and the complaints he presents with during the first meeting with doctor, most often this is a general practitioner (GP).

2. Mnemonic help - a list of medical terms giving hints to the affected anatomical region, the physiological deviations, basic pathophysiological reactions, processes and conditions leading to developing of the disease , and all addition factor - genetic, congenital, legal, ecomonic,social factoors,etc help or hinder the development of the disease.

3. On the basis of the patient's history and using the mnemonic help the students formulate several hypothesis for the possible ethilogical factors and pathogenitic mechanisms, leading to the suspected disease.

4. Patients History - a real history, taken by a physian,as some of the information irrelavant to the disease has been omited

5. Physical examition -systems, organs and functions, including inspetion, percussion, palpation and auscultation

6. Rearranging the hypothesis for the susptected disease by their probabylity, baking their hypthesis up using the only data form the presentation, history and physical examinarion. The students are to pick just the first 5 or 6 most probable diagnosys/diseases.

During the first part the tutor does not give any additinal information about the case, he just guides the discussion between the students. The students are woriking alone - formulating hypothesis and argumentating them by explaning the logical connetions between causes and results, namely: causes (and conditions) - altered structure - harmed fuction - clinical symptom - set of symptoms (syndroms) - disease. At the end of the first part the tutor gives oral direction to the students how to prepare for the second part. The studenst may use the time between the to parts to find additional information on the topic and gain some knowledge on the hypothesis that have been discussed, using either traditional form of education - textbooks, monographies,lectures, original scietific issues and review or any kind of infomation source including the world wide web.

\section{B. SECOND PART}

1. Set of laboratory results that the doctor seaching for the diagnosis may want to be made. Together with the labratory results, there are referent values also.

2. Additional fuctional and instrumental tests.As their is a great variaty the tests are limited to those that are most commonly used in practice and are relevant to the case, and giving maximum information, namely: blood pressure, ECG, EEG, EMG.X-ray, CT.MRI, ect.

3. The final rearrangement of the hypothesis considering all data from both the first and the second partand giving accurate diagnosis,corresponding to the particular clinical case. The students are encoured to give ideas about ethilogical or pathological treatment.

All discussions during the two parts are being recorded on the materials given by the tutor, so they can be used later for referance and self preparation.

\section{DISCUSSION AND RESULTS}

Until now, the faculty of pathophysiology has addapeted several clinical cases, including diseases like : diabetis mellitus, hipertension, cronic pancreatitis, peptic ulcer, chronic kidney failurem and brain vessel disease.

During the first part, the students manage to point out which are the major conplaints/syptoms form those the patient presents with during the meeting with the GP. Th analysis ot the data show that about $80 \%$ of the students take part in the discussion. During the discussion the general directions, for building hyposthesis about the possible disease, are formed.The mnemoinic help assist in forming of accurate methodological thinking in a real meeting with the patient. A small part of the students neglect the mnemonic help, which inevitably reflects on their work on the clinical case later on. The tutor encouges the students to write down as many diseases that can lead to those sympthoms as possible, without giving them any hints. The students should back up every hypothesis with explanation on what they have based their conclusions. This aims to develop clinical thinking in the situation of a game, where there is a history of an actual patient .The students should explain the pathophysiological patterns pointing causes and circumstances, risk factor and provoking moments for the suspected disease. The building of hypothesis contributes to the in-depth view of the clinical case in question. The experience showed that during discussion on the clinical case the students are motivate to write more than $20-25$ possible hypothesis, most of whom are able to argument the possibility of their suggestions relevantly adequate and logically true. It can be marked as a week point that the topic of the seminar directs the thinking of the students towards the disease without, sometimes without any objective facts baking 
this up. The role of the tutor here is to minimize the guessing by provoking a spirit of competitiveness, dividing the students into small teams of 3 or 2 . This aids the creating of ideas for analysis and oral and written communication between the students (10).

Other authors also report $(7,14)$ that by the history and the description of the physical examination of a real patient makes the situation more close to the real work of a doctor, which increases the students' interest and is relevantly successful.

At the same time, the tutor can evaluate the knowledge of the students by the reasoning of the hypothesis which are based on previously studied disciplines. The tutor can draw the students attention to gaps in their preparation and emphasize on the need for filling them up in the time between the two parts . In consonance with his professional competency, the tutor can catch if the student manage to use their knowledge on basic pathophysiology (nosology, types of pathological processes), in building a hypothesis. He can ask them directing questions to help the overcome any possible difficulties. The problems in reasoning the hypothesis are most often due to gaps in the comprehension of the anatomical and physiological substrate of the impairment, poor preparation on the studied unit in pathophysiology, or trying to use knowledge form introduction to internal diseases and surgery, as an end of its self, without paying attention to the pathophysiological mechanism. If time is adequately divided, at the end of the first part the tutor must have enough time to draw the attention and the preparation of the students to the next part so they understand the problems of the patient properly and thoroughly. Using the World Wide Web in preparation is of great value and very attractive (11). The experience with our work with clinical cases shows that with little exceptions (mainly foreign students, due to the language barrier), the students are active and motivated to take part in the discussion in the first part of the clinical case. They are able to identify the facts that they need the definite solving of the clinical case during the second part.

The results of the second part indicate some decrease in the activity of the students. Without any doubt, results of laboratory test with the referent values help remembering the values. These tests, in combination to all the additional functional and instrumental tests, that can be done give the future doctor the opportunity to get became acquainted with them, when it is need to be done, and what kind of information they can give. Unfortunately, because of the simultaneous studying of diagnostic imaging, clinical laboratory and pathophysiology and because of the specificity of the more complicated diagnostic investigations, the students encounter them in the pathophysiology seminars for the first time. The help the disciplines in question but it is brings about certain obstacles in leading active discussion in the second part of the clinical cases We give an account of the fact that predominantly more studious students, who have use the time between the two parts not only to work with the textbook and other reference books but also to exchange experience with other colleagues, to discuss with professors from different faculties take part, and of course to search in the internet (13). The role of the tutor-regulator here is of great significance. He is able to involve the maximum number of student in the discussion, to put accent on the risk factors and socially significant diseases and to contribute to increasing the activity of the students. Delaying maximally the moment of reaching the definite diagnosis, helping the students to interpret the lab results and the functional-instrumental tests properly, the tutor draws the attention to rearranging the hypothesis for the corresponding disease, forming, in the course of discussion, the method to differentiate between the significant and in significant complaints of the patient, emphasizes on the problems of the patients which should be looked at in a medico-biological, and socially legal aspect (9). Thus he maintains the interest and motivation for active position of the students till the end of the second part.

\section{CONCLUSION}

Nevertheless our modest experience in this field, bringing in clinical questions during seminar lessons as a part of the course of pathophysiology we have developed I applied for the needs of teaching a convenient, attractive and beneficial to the students form of education. It gives the student a wonderful possibility to build a bridge between preclinical studies and the work of the doctor with immediate contact with the patient.

\section{REFERENCES}

1. Blumberg, Ph., J. Michael, H. Zeitz. Role of student generated learning issues in problem - based learning. Teaching and Learning in Medicine, 1990, vol. 2, N 3, pp 149-154.

2. Colliver, J. Effectiveness of problem-based learning curricula research and theory. Acad. Med., 2000, vol. 75, N 3, pp 259-266.

3. Conncil of Europe Committee of Ministers, Recommendation N R (90) 21 of the Committee to Member States on Training Strategies for Health Information System, adopled by the Committee of Ministers on the 18 October 1990.

4. Dimova, S., M. Marinov, K. Demireva. Pathophysoilogy and the new strategies for medical education. Bulg. Medicine, 2002, vol. 10, N 2, pp 28-30.

5. Goodman, L. et al. An experiment in medical education. JAMA, 1991, vol. 265, N 18, pp 2373-2376.

6. Goswami, U Neuroscience and education: from research to practice? Nat Rev. Neurosci., 2006, vol. 7, N 5, pp 406-411.

7. Hudson, J. N., P. Bucvley, I.C. McMillen. Linking cardiovascular theory to practice in an undergraduate medical curriculum. Adv. Physiol. Educ., 2001, vol. 25, N 1-4, pp 193-201.

8. Norman, G., H. Schmidt. Effectiveness of problem-based learning curricula: theory, practice and paper darts. Med Educ., 2000, vol. 34, N 9, pp 721-728. 
Radev R. Zl., G. Bekyarova, M. Marinov ...

9. Pulanic, D., H. Vrazic, Cuk, M. Petroveski. Ethiks in medicine: students' opinions on disclosure of true diagnosis. Croat. Med. J., 2002, vol. 43, N 1, pp 75-79.

10. Rivers, D. B. Using a course - long theme for ingucry - based laboratories in a comparative ghysiology course. Adv. Physiol. Educ., 2002, vol. 26, N 1-4, pp 317 - 326.

11. Sarbadhikari, S. N. Basic medical science must include medical informatics. Indian J. Physiol. Pharmacol., 2004, vol. 48, N 4, pp 395-408.
12. Suwandwela, Ch. et al. Long. Term ontcome of innovative curricular tracks used in four conntries. Acad. Med., 1993, vol. 68, N 2, pp 128-132.

13. Valdum, C., CH. Zhao, D. Chen. Are current textbooks good enongh for physiology education? For example, the ECL cells are missing. Adv. Physiol. Educ., 2001, vol. 25, N 1-4, pp 123-126.

14. Wolters, M. R. Problem - based learning within entocrine physiology lectures. Adv. Physiol. Educ., 2001, vol. 25, N 1-4, pp 225-227.

15. Zeitz H., H. Paul. The alternative curriculum. Chicago Medicine, 1990, vol. 93, N 12, pp 16-20. 